\title{
The impact of body mass index, central obesity and physical activity on lung function: results of the EpiHealth study
}

\author{
Magnus Svartengren (1) ${ }^{1}$, Gui-Hong Cai ${ }^{1,2}$, Andrei Malinovschi (i) ${ }^{3}$, \\ Jenny Theorell-Haglöw (102 ${ }^{2}$, Christer Janson (102 ${ }^{2}$, Sölve Elmståhl ${ }^{4,5}$, Lars Lind ${ }^{6}$, \\ Erik Lampa ${ }^{7}$ and Eva Lindberg ${ }^{2}$
}

\begin{abstract}
Affiliations: 'Dept of Medical Sciences, Occupational and Environmental Medicine, Uppsala University, Uppsala, Sweden. ${ }^{2}$ Dept of Medical Sciences, Respiratory, Allergy and Sleep Research, Uppsala University, Uppsala, Sweden. ${ }^{3}$ Dept of Medical Sciences, Clinical Physiology, Uppsala University, Uppsala, Sweden. ${ }^{4}$ Dept of Health Sciences, Division of Geriatric Medicine, Lund University, Lund, Sweden. ${ }^{5}$ Clinical Research Centre (CRC), Skåne University Hospital, Malmö, Sweden. ${ }^{6}$ Dept of Medical Sciences, Cardiovascular Epidemiology, Uppsala University, Uppsala, Sweden. ${ }^{7}$ Uppsala Clinical Research Center (UCR), Uppsala University, Uppsala, Sweden.
\end{abstract}

Correspondence: Magnus Svartengren, Dept of Medical Sciences, Occupational and Environmental Medicine, Uppsala University, Uppsala, Sweden, Akademiska sjukhuset, FE77, Box 6363, 75135 Uppsala, Sweden. E-mail: magnus.svartengrenamedsci.uu.se

\section{ABSTRACT}

Study objectives: Obesity is often associated with lower lung function; however, the interaction of lung function with central obesity and physical inactivity is less clear. As such, we investigated the effect on lung function of body size (body mass index (BMI)), central obesity (waist circumference (WC)) and selfreported physical activity.

Methods: Lung function, height, weight and WC were measured in 22743 participants (12791 women), aged 45-75 years, from the EpiHealth cohort study. Physical activity, gender and educational level were assessed using a questionnaire.

Results: Obesity, central obesity and physical inactivity were all associated with lower forced expiratory volume in $1 \mathrm{~s}\left(\mathrm{FEV}_{1}\right)$ and forced vital capacity $(\mathrm{FVC})$. However, in participants without central obesity there was an increase in both $\mathrm{FEV}_{1}$ and FVC by BMI (\% predicted FVC increasing from median $98 \%$, interquartile range (IQR) $89-110 \%$ in underweight participants (BMI <20) to $103 \%$, IQR $94-113 \%$ in obese participants $(\mathrm{BMI} \geqslant 30)$ ). In contrast, there was a decrease in $\%$ predicted FVC in participants with central obesity (from 98\%, IQR $89-109 \%$ in the normal weight group to $95 \%$, IQR $85-105 \%$ in the obese weight group). We further found a negative association between physical activity and lung function among those with low and high levels of physical activity (\% predicted $\mathrm{FEV}_{1}$ 97\%, IQR 86-107\% versus 103\%, IQR 94-113\%, respectively and \% predicted FVC 96\%, IQR 85-106\% versus 103\%, IQR 94-113\%, respectively). All results remained when calculated by z-scores.

Conclusions: The association between BMI and lung function is dependent on the presence of central obesity. Independent of obesity, there is an association between physical activity and lung function.

@ERSpublications

BMI and central obesity are related to lung function in the middle-aged and elderly. BMI association with lung function is dependent on the presence of central obesity, while the association of physical activity and lung function is independent of obesity. https://bit.ly/3eQl86C

Cite this article as: Svartengren M, Cai G-H, Malinovschi A, et al. The impact of body mass index, central obesity and physical activity on lung function: results of the EpiHealth study. ERJ Open Res 2020; 6: 00214-2020 [https://doi.org/10.1183/23120541.00214-2020].

Received: 24 April 2020 | Accepted after revision: 3 June 2020

Copyright $\odot$ ERS 2020. This article is open access and distributed under the terms of the Creative Commons Attribution Non-Commercial Licence 4.0 


\section{Introduction}

Over the past decades, the rising prevalence of excess weight (both overweight and obesity) has become a major public health challenge across the world [1]. A recent population-based study involving subjects from eight European centres (the EMAS study) showed that about half the subjects were overweight or obese, with an even higher prevalence in Eastern transitional countries (Poland, Hungary and Estonia) [2]. Globally, the proportion of adults with a body mass index (BMI) of $\geqslant 25 \mathrm{~kg} \cdot \mathrm{m}^{-2}$ increased from $29 \%$ in 1980 to $37 \%$ in 2013 for men and from 30\% to 38\% for women [1]. Obesity is associated with various diseases and is an important cardiovascular risk factor. The aetiology of obesity is complex and multifactorial, and results from the interaction of genes with the environment, lifestyle and emotional factors [3].

Several studies have reported a reduction in lung volume and capacity in obese individuals as compared to the non-obese [4-6]. The accumulation of fat in the body causes changes in respiratory physiology, with consequent impairment of various lung function parameters [3]. Different patterns of body fat distribution affect the function of the respiratory system differentially and negatively [7]. There are studies claiming that abdominal obesity markers like waist circumference (WC), waist-hip ratio and abdominal height are more important and better predictors of pulmonary function than BMI, since BMI does not provide information on body fat distribution [8-11].

The association between obesity and low lung function may partly be related to low physical activity in many obese subjects [12]. This is supported by data from the European Community Respiratory Health Survey (ECRHS), which show that a high level of physical activity is associated with higher lung function [13]. Higher physical activity is also associated with less lung function decline and lower chronic obstructive pulmonary disease (COPD) risk in an analysis from the Copenhagen City study [14].

To date, there is no study that shows the associations between BMI level, central obesity and lung function that has also studied the combined effect of BMI and central obesity on lung function, especially using a restricted cubic spline (RCS) to provide a method to intuitively represent a nonlinear relationship for this type of association [15]. With this in mind and considering the impact that obesity and central obesity might have on lung function, the present investigation aimed to study the relationship between BMI, WC, self-reported physical activity level and lung function in a large population study of the middle-aged and elderly in Sweden. Moreover, we also aimed to quantify the associations between obesity, central obesity and a combined effect of obesity and central obesity with lung function, using RCS functions adjusting for potential confounders.

\section{Material and methods}

Cohort description

The present study utilised data from the Swedish EpiHealth cohort study (www.epihealth.se) [16]. The EpiHealth study started in 2011, with the primary objective being to study how interactions between lifestyle factors and genotypes contribute to the development of common disorders in humans (such as cardiovascular and respiratory diseases). To realise this aim, participants derived from a middle-aged and elderly Swedish population filled out an internet-based questionnaire, as well as visited one of two Swedish test centres (located in Malmö and Uppsala) [16-18]. In the present study, subjects were excluded if they had missing data on weight or height, or if they had invalid data for lung function variables. A total of 22743 participants (aged 45-75 years) were considered eligible for the present analysis. The Ethics Committee at Uppsala University (Dnr 2010/402) approved the study and all the participants gave their written informed consent to participate.

\section{Body mass index and central obesity}

Weight, height and WC were measured at the test centres. BMI was calculated as body mass divided by squared height $\left(\mathrm{kg} \cdot \mathrm{m}^{-2}\right)$. Based on BMI, the subjects were categorised as underweight $\left(\mathrm{BMI}<20 \mathrm{~kg} \cdot \mathrm{m}^{-2}\right)$, normal weight (BMI 20-24.99 $\mathrm{kg} \cdot \mathrm{m}^{-2}$ ), overweight (BMI $25-29.99 \mathrm{~kg} \cdot \mathrm{m}^{-2}$ ) and obese $\left(\mathrm{BMI} \geqslant 30 \mathrm{~kg} \cdot \mathrm{m}^{-2}\right.$ ). WC was measured midway between the lower rib margin and the anterior superior iliac crest at the end of normal exhalation while standing. A waist circumference of $\geqslant 88 \mathrm{~cm}$ for women and $\geqslant 102 \mathrm{~cm}$ for men was used to define central obesity according to the National Cholesterol Education Program criteria [19].

\section{Lung function}

A simplified resting lung function test was performed using a MiniSpir spirometer (Medical International Research, Waukesha, WI, USA) to measure forced expiratory volume in $1 \mathrm{~s}\left(\mathrm{FEV}_{1}\right)$ and forced vital capacity (FVC) [20]. Briefly, the pulmonary function test was conducted in a standing position following standard procedures and at least three manoeuvres were performed, with the best measure of $\mathrm{FEV}_{1}$ and FVC being recorded. The 2012 Global Lung Function Initiative (GLI) equations [21, 22] were applied for generating the predicted values and $\mathrm{z}$-scores for $\mathrm{FEV}_{1}, \mathrm{FVC}$ and $\mathrm{FEV}_{1} / \mathrm{FVC}$ ratio. 


\section{Physical activity}

The subjects reported their level of physical activity during leisure time on a seven-point scale. In the statistical analysis, the level of physical activity during leisure time was categorised into three groups. A low level of physical activity was defined as score one (mostly sedentary, sometimes walking, or lighter gardening or easy household work). A medium level was defined as score two (some physical activity, such as walking, more strenuous exercise up to $\left.2 \mathrm{~h} \cdot \mathrm{week}^{-1}\right)$. A high physical activity level was defined as score three (more strenuous exercise at least $3 \mathrm{~h} \cdot \mathrm{week}^{-1}$ ). The scale is modified after the fashion of ByBERG et al. [23]. Occupational physical activity was measured with a five-point Likert scale (1. mostly sitting; 2 . not stated; 3. mostly walking and standing; 4 . not stated; 5 . heavy manual labour).

\section{Other lifestyle factors}

The participants' smoking habits at the time of the survey (non-smokers versus former smokers versus current smokers), educational status and civil status (married versus not married) were assessed using the internet-based questionnaire. The participants' educational status was defined as follows: primary and elementary school (up to 9 years of formal schooling) versus secondary high school (up to 12 years of formal schooling) versus university.

\section{Statistical analyses}

The associations between BMI, WC, physical activity and the z-scores of $\mathrm{FEV}_{1}$ and FVC were analysed using a cumulative probability model (CPM) [24]. The CPM is attractive since it uses the ordering of the response variable and is therefore invariant to monotonic transformations of the response. It also fits the entire conditional cumulative distribution, instead of focusing on, for example, the conditional expected value (as in ordinary least squares regression) or conditional quantiles (as in quantile regression), quantities which can be derived once the cumulative distribution is modelled.

Continuous variables were modelled using RCS with three knots placed at the 10th, 50th and 90th percentiles of the variables' distributions. Included in the models were BMI, WC and their interaction, education (elementary school, secondary high school, university), smoking status (never, former, current) and leisure time physical activity (low, medium, high). A gender interaction was also included to obtain gender specific estimates of all associations.

Model fit was assessed visually by inspecting quantile-quantile plots of the probability scale residuals resulting from the regression models. A sensitivity analysis was performed, where work-related physical activity was added to the models while restricting the sample to the subset of participants who were not retired or unemployed $(n=14135)$. The importance of each variable in the model was assessed using the variable's Chi-squared value and subtracting the degrees of freedom. All analyses were performed using $\mathrm{R}$ software version 3.6.0 [25] using functions from the add-on package rms [26].

\section{TABLE 1 Characteristics of the study participants in total and stratified by obesity level and central obesity}

\begin{tabular}{|c|c|c|c|c|c|}
\hline \multirow[t]{2}{*}{ Characteristic } & \multirow[t]{2}{*}{ Category } & \multirow[t]{2}{*}{ Total $(n=22743)$} & \multicolumn{3}{|c|}{ Obesity } \\
\hline & & & Mild $^{\#}(n=3454)$ & Morbid" ( $n=128$ ) & Central $^{+}(\mathrm{n}=9327)$ \\
\hline Gender & Men & 43.8 & 47.8 & 27.3 & 34.5 \\
\hline \multirow[t]{3}{*}{ Age $^{\S}$ years } & $<55$ & 28.1 & 27.2 & 34.3 & 22.9 \\
\hline & $55-64$ & 31.8 & 32.6 & 32.8 & 32.3 \\
\hline & $\geqslant 65$ & 40.1 & 40.4 & 32.8 & 44.8 \\
\hline Smoking status & Current & 8.0 & 7.9 & 7.3 & 8.8 \\
\hline \multirow[t]{3}{*}{ Leisure time physical activity } & Low & 6.0 & 12.3 & 21.1 & 9.0 \\
\hline & Medium & 75.9 & 78.0 & 76.4 & 80.9 \\
\hline & High & 18.1 & 9.6 & 2.4 & 10.1 \\
\hline \multirow[t]{2}{*}{ Education } & Primary and elementary school & 27.4 & 34.0 & 28.0 & 32.5 \\
\hline & Secondary high school & 25.6 & 30.1 & 28.8 & 26.8 \\
\hline
\end{tabular}


TABLE 2 Lung function variables stratified by obesity, central obesity and level of leisure time physical activity

\begin{tabular}{|c|c|c|c|c|c|c|c|c|c|}
\hline \multirow[t]{2}{*}{ Variable } & \multirow{2}{*}{$\begin{array}{c}\text { Total }(n=22 \\
743)\end{array}$} & \multicolumn{3}{|c|}{ Obesity } & \multicolumn{2}{|c|}{ Central obesity } & \multicolumn{3}{|c|}{ Leisure time physical activity } \\
\hline & & $\mathrm{No}^{\#}(\mathrm{n}=18550)$ & Mild" ( $n=3454$ ) & Morbid $^{+}(n=128)$ & No $(n=13412)$ & $Y_{e s}^{\S}(n=9327)$ & High ( $n=4012$ ) & $\begin{array}{c}\text { Medium ( } n=16 \\
805 \text { ) }\end{array}$ & Low $(n=1326)$ \\
\hline FEV $1 \%$ predicted & $100(91-111)$ & $101(98-112)$ & 98 (88-109) & $88(80-100)$ & $102(93-112)$ & $99(88-109)$ & $103(94-113)$ & $101(91-111)$ & $97(86-107)$ \\
\hline FVC $\%$ predicted & $100(91-111)$ & $101(92-111)$ & $95(86-106)$ & $85(78-96)$ & $102(93-112)$ & 97 (87-107) & $103(94-113)$ & $100(90-110)$ & $96(85-106)$ \\
\hline $\begin{array}{c}\mathrm{FEV}_{1} / \mathrm{FVC} \% \\
\text { predicted }\end{array}$ & $100(96-110)$ & $100(95-110)$ & 103 (98-108) & $104(75-85)$ & $100(95-110)$ & $100(97-110)$ & 101 (95-105) & $101(96-106)$ & 102 (95-107) \\
\hline $\mathrm{FEV}_{1}$ z-score & $\begin{array}{c}0.06(-0.62 \text { to } \\
0.77)\end{array}$ & $\begin{array}{c}0.10(-0.56 \text { to } \\
0.80)\end{array}$ & $\begin{array}{c}-0.12(-0.84 \text { to } \\
0.60)\end{array}$ & $\begin{array}{c}-0.82(-1.37 \text { to } \\
-0.01)\end{array}$ & $\begin{array}{c}0.14(-0.50 \text { to } \\
0.86)\end{array}$ & $\begin{array}{c}-0.08(-0.79 \text { to } \\
0.61)\end{array}$ & $\begin{array}{c}0.19(-0.42 \text { to } \\
0.91)\end{array}$ & $\begin{array}{c}0.04(-0.64 \text { to } \\
0.75)\end{array}$ & $\begin{array}{c}-0.22(-0.94 \text { to } \\
0.52)\end{array}$ \\
\hline FVC z-score & $\begin{array}{c}0.00(-0.64 \text { to } \\
0.70)\end{array}$ & $\begin{array}{c}0.07(-0.56 \text { to } \\
0.76)\end{array}$ & $\begin{array}{c}-0.31(-0.97 \text { to } \\
0.39)\end{array}$ & $\begin{array}{c}-1.05(-1.58 \text { to } \\
-0.22)\end{array}$ & $\begin{array}{c}0.14(-0.48 \text { to } \\
0.84)\end{array}$ & $\begin{array}{c}-0.21(-0.86 \text { to } \\
0.48)\end{array}$ & $\begin{array}{c}0.20(-0.43 \text { to } \\
0.88)\end{array}$ & $\begin{array}{c}-0.02(-0.65 \text { to } \\
0.67)\end{array}$ & $\begin{array}{c}-0.31(-1.03 \text { to } \\
0.45)\end{array}$ \\
\hline $\begin{array}{r}\mathrm{FEV}_{1} / \mathrm{FVC} \\
\text { z-score }\end{array}$ & $\begin{array}{c}0.06(-0.57 \text { to } \\
0.64)\end{array}$ & $\begin{array}{c}0.02(-0.62 \text { to } \\
0.58)\end{array}$ & $\begin{array}{c}0.30(-0.31 \text { to } \\
0.86)\end{array}$ & $\begin{array}{c}0.45(-0.28 \text { to } \\
0.90)\end{array}$ & $\begin{array}{c}-0.01(-0.65 \text { to } \\
0.56)\end{array}$ & $\begin{array}{c}0.18(-0.45 \text { to } \\
0.74)\end{array}$ & $\begin{array}{c}0.03(-0.64 \text { to } \\
0.58)\end{array}$ & $\begin{array}{c}0.07(-0.55 \text { to } \\
0.63)\end{array}$ & $\begin{array}{c}0.14(-0.62 \text { to } \\
0.77)\end{array}$ \\
\hline
\end{tabular}

Data are presented as median (IQR). $\mathrm{FEV}_{1}$ : forced expiratory volume in $1 \mathrm{~s}$; FVC: forced vital capacity; IQR: interquartile range. ${ }^{\#}$ : body mass index (BMI) <30 kg. ${ }^{-2}$; : BMI $30-39 \mathrm{~kg} \cdot \mathrm{m}^{-2} ;{ }^{+}: \mathrm{BMI} \geqslant 40 \mathrm{~kg} \cdot \mathrm{m}^{-2} ;{ }^{\S}:$ waist circumference $(\mathrm{WC}) \geqslant 88 \mathrm{~cm}$ for women and $\geqslant 102 \mathrm{~cm}$ for men.

TABLE 3 Lung function variables stratified by body mass index (BMI) category in participants with and without central obesity

\begin{tabular}{|c|c|c|c|c|c|c|c|c|}
\hline \multirow[t]{2}{*}{ Variable } & \multicolumn{4}{|c|}{ Participants without central obesity \# $(n=13412$ ) } & \multicolumn{4}{|c|}{ Participants with central obesity ${ }^{\#}(n=9327$ ) } \\
\hline & $\begin{array}{l}\text { Underweight" } \\
\text { (n=541) }\end{array}$ & $\begin{array}{c}\text { Normal weight }{ }^{+} \\
(n=7515)\end{array}$ & $\begin{array}{l}\text { Overweight }^{\S} \\
\text { (n=4924) }\end{array}$ & $\begin{array}{l}\text { Mild obesity }{ }^{f} \\
\text { (n=177) }\end{array}$ & $\begin{array}{l}\text { Normal weight }{ }^{+} \\
\quad(n=914)\end{array}$ & $\begin{array}{l}\text { Overweight }^{\S} \\
(n=4654)\end{array}$ & $\begin{array}{l}\text { Mild obesity } \\
\text { (n=3277) }\end{array}$ & $\begin{array}{l}\text { Morbid obesity \#\# } \\
\text { ( } n=128)\end{array}$ \\
\hline $\begin{array}{l}\mathrm{FEV}_{1} \% \\
\text { predicted }\end{array}$ & $99(90-109)$ & $102(93-112)$ & 103 (93-113) & $105(96-115)$ & $99(89-109)$ & $100(90-110)$ & $98(88-109)$ & $88(80-100)$ \\
\hline FVC $\%$ predicted & $100(91-111)$ & 102 (94-113) & $102(92-112)$ & 103 (94-113) & 98 (89-109) & 98 (89-109) & 95 (86-106) & 85 (78-96) \\
\hline $\begin{array}{l}\mathrm{FEV}_{1} / \mathrm{FVC} \% \\
\text { predicted }\end{array}$ & 98 (92-103) & 100 (94-105) & $101(96-106)$ & $104(100-108)$ & 100 (94-105) & $102(96-106)$ & 103 (98-108) & 104 (98-108) \\
\hline $\mathrm{FEV}_{1}$ z-score & $\begin{array}{c}-0.06(-0.73 \text { to } \\
0.60)\end{array}$ & $0.12(-0.51$ to 0.82$)$ & $\begin{array}{c}0.19(-0.47 \text { to } \\
0.92)\end{array}$ & $\begin{array}{c}0.38(-0.26 \text { to } \\
1.10)\end{array}$ & $\begin{array}{c}-0.06(-0.73 \text { to } \\
0.59)\end{array}$ & $\begin{array}{c}0.00(-0.69 \text { to } \\
0.67)\end{array}$ & $\begin{array}{c}-0.12(-0.84 \text { to } \\
0.60)\end{array}$ & $\begin{array}{c}-0.82(-1.37 \text { to } \\
-0.01)\end{array}$ \\
\hline FVC z-score & $0.00(-0.61$ to 0.74$)$ & $0.15(-0.44$ to 0.85$)$ & $\begin{array}{c}0.13(-0.51 \text { to } \\
0.83)\end{array}$ & $\begin{array}{c}0.17(-0.47 \text { to } \\
0.92)\end{array}$ & $\begin{array}{c}-1.10(-0.72 \text { to } \\
0.61)\end{array}$ & $\begin{array}{c}-0.12(-0.74 \text { to } \\
0.57)\end{array}$ & $\begin{array}{c}-0.31(-0.97 \text { to } \\
0.39)\end{array}$ & $\begin{array}{c}-1.05(-1.58 \text { to } \\
-0.22)\end{array}$ \\
\hline $\begin{array}{r}\mathrm{FEV}_{1} / \mathrm{FVC} \\
\text { z-score }\end{array}$ & $\begin{array}{c}-0.27(-1.00 \text { to } \\
0.30)\end{array}$ & $\begin{array}{c}-0.08(-0.69 \text { to } \\
0.47)\end{array}$ & $\begin{array}{c}0.12(-0.53 \text { to } \\
0.68)\end{array}$ & $\begin{array}{c}0.39(-0.08 \text { to } \\
0.90)\end{array}$ & $\begin{array}{c}-0.07(-0.74 \text { to } \\
0.48)\end{array}$ & $\begin{array}{c}0.13(-0.48 \text { to } \\
0.69)\end{array}$ & $\begin{array}{c}0.30(-0.31 \text { to } \\
0.86)\end{array}$ & $0.44(-0.28$ to 0.90$)$ \\
\hline
\end{tabular}

Data are presented as median (IQR). The combination of underweight and central obesity is not presented since only two subjects were in this category. $\mathrm{FEV}_{1}$ : forced expiratory volume in $1 \mathrm{~s}$; FVC: forced vital capacity; IQR: interquartile range. ${ }^{\#}$ : waist circumference $(\mathrm{WC}) \geqslant 88 \mathrm{~cm}$ for women and $\geqslant 102 \mathrm{~cm}$ for $\mathrm{men} ;{ }^{\uparrow}: \mathrm{BMI}<20 \mathrm{~kg} \cdot \mathrm{m}^{-2}$; ${ }^{+}: \mathrm{BMI} 20-24 \mathrm{~kg} \cdot \mathrm{m}^{-2} ;{ }^{\S}: \mathrm{BMI}$ $25-29 \mathrm{~kg} \cdot \mathrm{m}^{-2} ;{ }^{f}: \mathrm{BMI} 30-39 \mathrm{~kg} \cdot \mathrm{m}^{-2} ;{ }^{\# \#}: \mathrm{BMI} \geqslant 40 \mathrm{~kg} \cdot \mathrm{m}^{-2}$ 

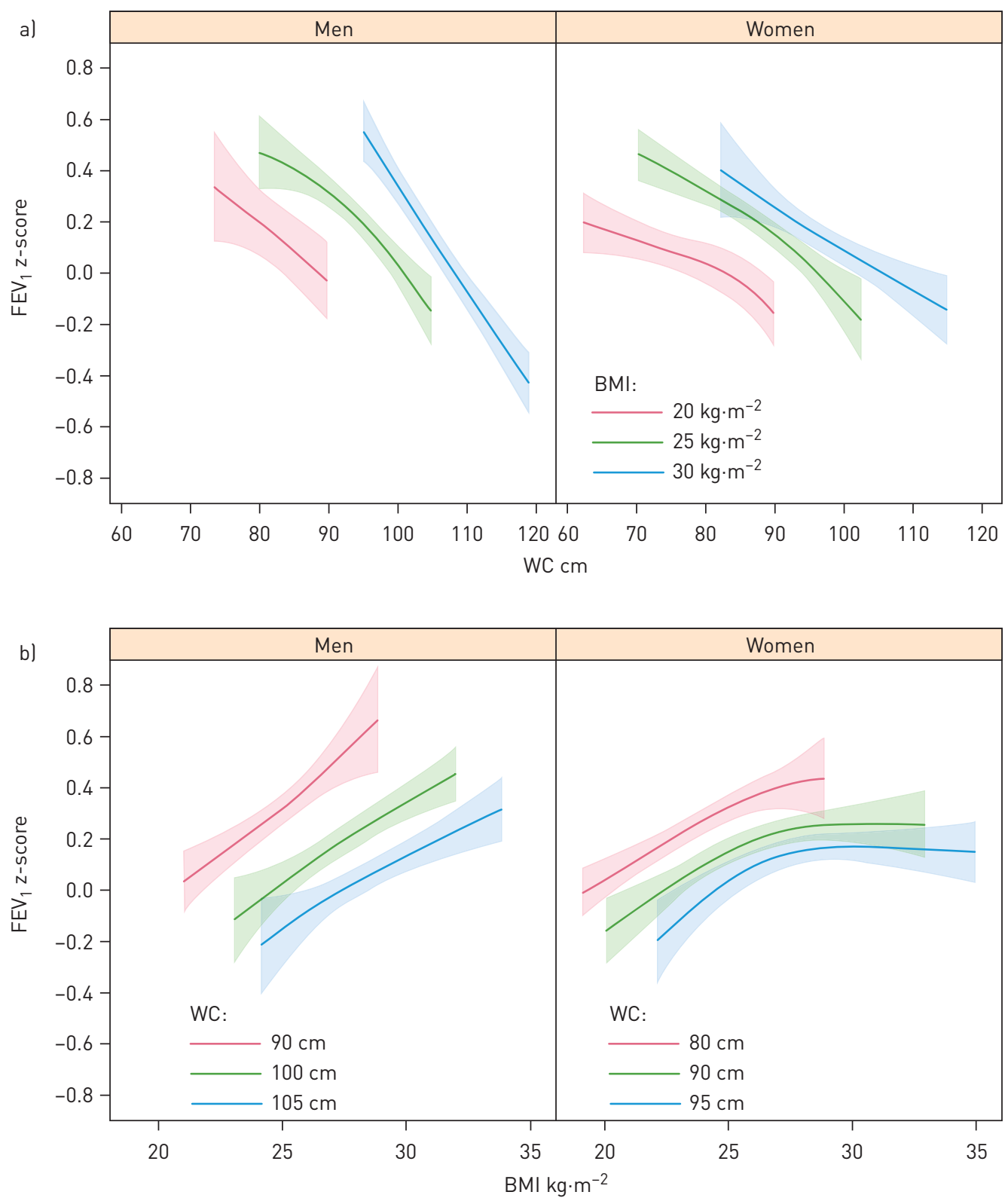

FIGURE 1 a) Forced expiratory volume in $1 \mathrm{~s}\left(\mathrm{FEV}_{1}\right)$ z-scores and $95 \%$ confidence intervals $(\mathrm{Cls})$ in men and women as a function of waist circumference (WC) predicated on body mass index (BMI) values of 20, 25 and $30 \mathrm{~kg} \cdot \mathrm{m}^{-2}$ (chosen to correspond to the widely used cut-offs for the normal weight, overweight and obese categories). b) $\mathrm{FEV}_{1} \mathrm{z}$-scores and $95 \% \mathrm{Cls}$ in men and women as a function of BMl predicated on WC (in $\mathrm{cm}$ ) corresponding roughly to the gender specific 10th, 50th and 90th percentiles rounded to the nearest multiple of five. All estimates were adjusted for smoking status and education.

\section{Results}

\section{Population data}

Characteristics of the participants in total and by obesity and central obesity are given in table 1 . In the whole study population, $47 \%$ of men and $53 \%$ of women were obese and $34 \%$ of men and $66 \%$ women were classified as having central obesity. Both obesity and central obesity were related to a lower level of leisure time physical activity.

\section{Lung function in relation to BMI and central obesity}

The results of lung function variables by general obesity, central obesity and level of leisure time physical activity are shown in table 2 . The participants who had no general obesity and no central obesity had higher $\mathrm{FEV}_{1}$ and FVC compared to those with general or central obesity. There were no effects on the $\mathrm{FEV}_{1} / \mathrm{FVC}$ ratio. 

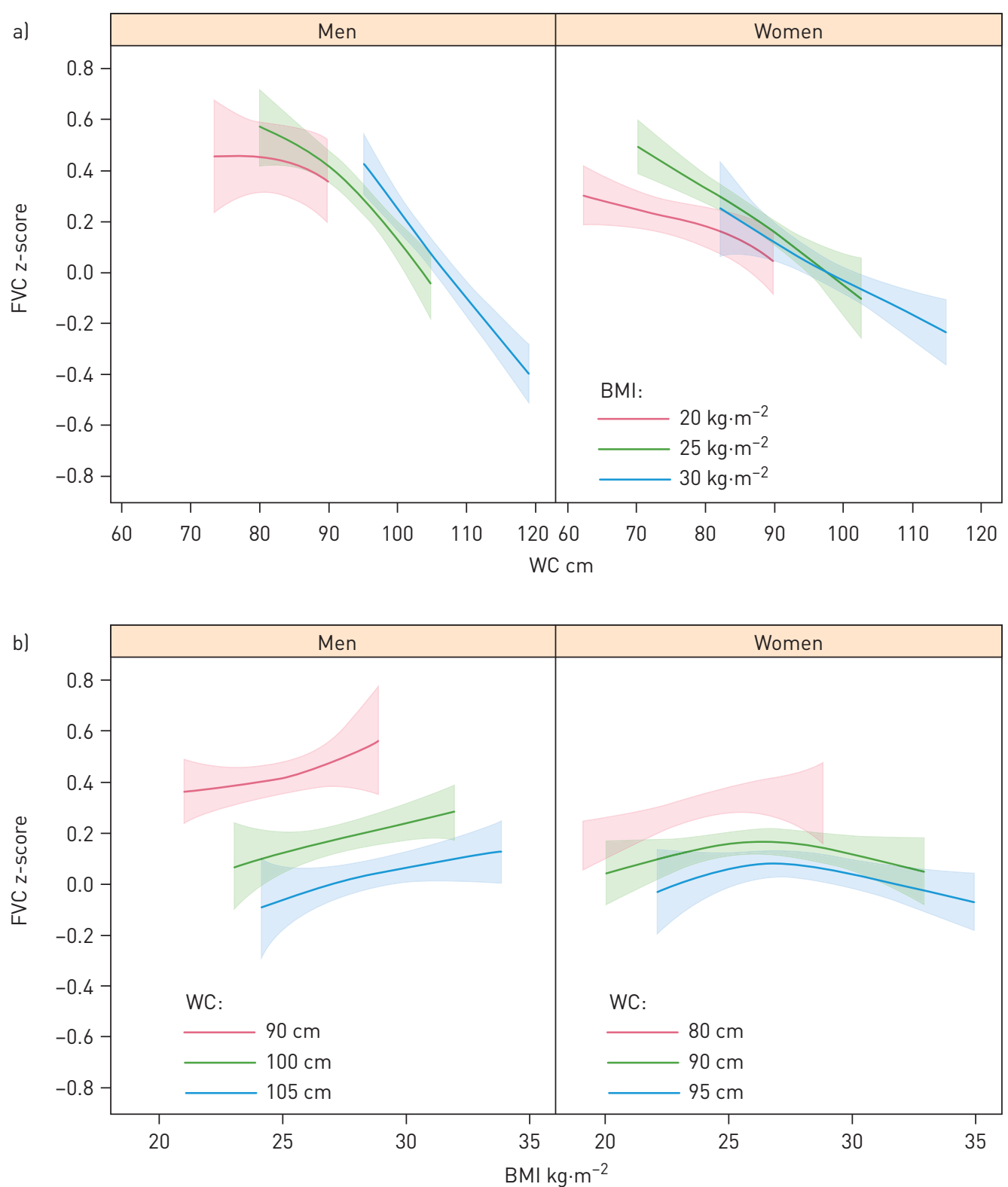

FIGURE 2 a) Estimated forced vital capacity (FVC) z-scores and $95 \%$ confidence intervals (Cls) in men and women as a function of waist circumference (WC) predicated on body mass index (BMI) values of 20, 25 and $30 \mathrm{~kg} \cdot \mathrm{m}^{-2}$ (chosen to correspond to the widely used cut-offs for the normal weight, overweight and obese categories). b) Estimated FVC z-scores and $95 \% \mathrm{Cls}$ in men and women as a function of BMI predicated on WC (in $\mathrm{cm}$ ) corresponding roughly to the gender specific 10th, 50th and 90th percentiles rounded to the nearest multiple of five. All estimates were adjusted for smoking status and education.

Lung function variables by BMI category in participants with and without central obesity are shown in table 3. For those without central obesity, there was a trend of increasing $\mathrm{FEV}_{1}$ and $\mathrm{FVC}$ with increasing $\mathrm{BMI}$ category. Also, $\mathrm{FEV}_{1} / \mathrm{FVC}$ ratio increased with $\mathrm{BMI}$ category. There was an opposite trend of decreasing $\mathrm{FEV}_{1}$ and $\mathrm{FVC}$ with increasing central obesity.

\section{Results from the regression analyses investigating associations between BMI, central obesity and} lung function

The interaction between BMI and WC in the models results in three-dimensional surfaces of estimated lung function values for any combination of the two variables.

Increased WC was associated with lower $\mathrm{FEV}_{1}$ in both men and women regardless of BMI (figure 1). There was no interaction with gender $(\mathrm{p}=0.234$ for the three-way interaction between gender, BMI and WC). On the contrary, as shown in the lower panel of figure 1, increased BMI was associated with higher 
TABLE 4 Estimated differences in forced expiratory volume in $1 \mathrm{~s}\left(\mathrm{FEV}_{1}\right)$ with $95 \%$ confidence intervals $(\mathrm{Cls})$ stratified by both changes in body mass index (BMI) and waist circumference (WC) at a fixed level of the other variable

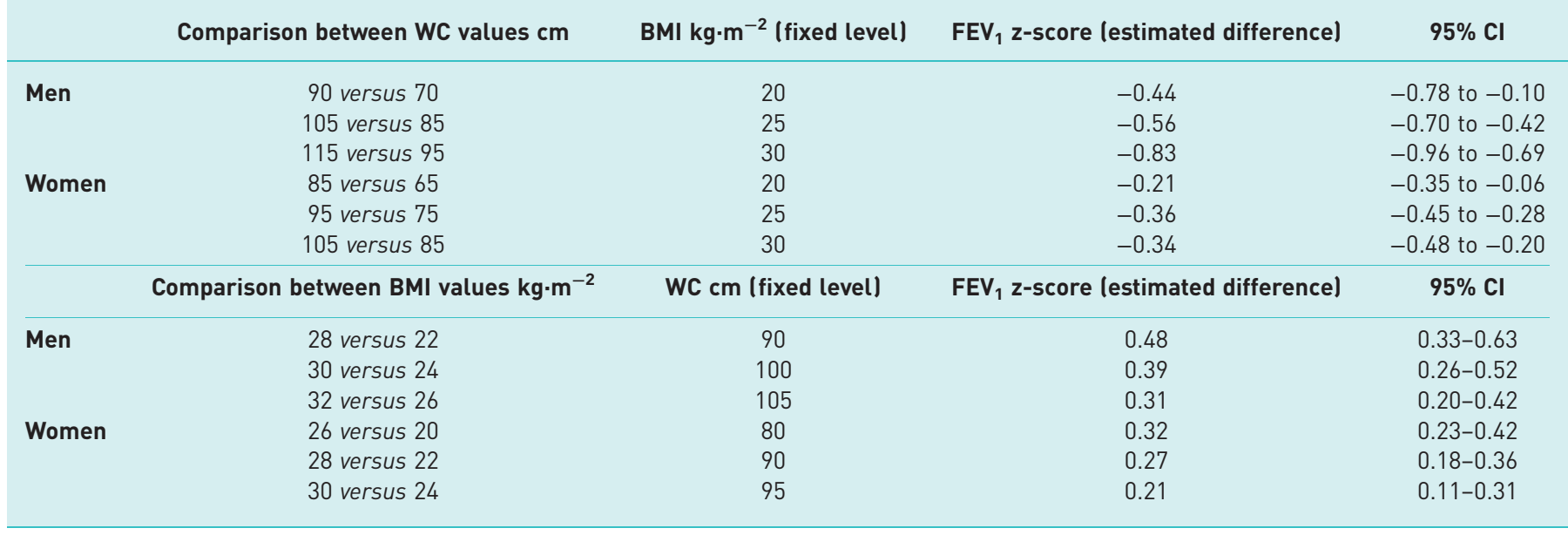

$\mathrm{FEV}_{1}$ when keeping $\mathrm{WC}$ and all the adjustment variables constant. There was a trend for non-linear association in women ( $\mathrm{p}=0.066$ for non-linear terms), as $\mathrm{FEV}_{1}$ seems to increase with increasing BMI but flattens out as BMI gets higher. Similar results were found for FVC, which decreased with increasing WC (figure 2a) and increased with increasing BMI (figure 2b) when the other anthropometric variables were kept constant. Table 4 shows estimated differences in $\mathrm{FEV}_{1}$ for a $20 \mathrm{~cm}$ increase in WC and for a six unit increase in BMI. By comparing the Chi-squared-df values for WC and BMI within both models, WC was more important than BMI although both variables were important in the models $(\mathrm{p}<0.001$ for both variables in both models). Data provided no evidence for the existence of an interaction between BMI and $\mathrm{WC}\left(\mathrm{p}=0.145\right.$ for $\mathrm{FEV}_{1}$ and $\mathrm{p}=0.481$ for $\mathrm{FVC}$ ).

\section{Physical activity and lung function}

For leisure time physical activity, participants with a high physical activity level had the highest values for both $\mathrm{FEV}_{1}$ and FVC, followed by those with a medium level (table 2). There was no effect on the $\mathrm{FEV}_{1} /$ FVC ratio. The association between physical activity and lung function was also seen in both men and women after adjusting for BMI, WC, gender, smoking status and education (figure 3). The associations remained after work-related physical activity was included in the models. Work-related physical activity explained part of the variation in $\mathrm{FEV}_{1}$ (Chi-squared- $\mathrm{df}=6.8$ compared to leisure time physical activity Chi-squared- $\mathrm{df}=35.0$ ), while no evidence of such an association was found for FVC (Chi-squared- $\mathrm{df}=2.3$ compared to leisure time physical activity Chi-squared-df=43.5).

\section{Discussion}

The main finding in this study is that in this middle-aged to elderly population there is a positive association between BMI and lung function, measured as FVC and $\mathrm{FEV}_{1}$, as long as there is no central obesity. Central obesity, on the other hand, is associated with a decrease in lung function. As such, the previous often-reported negative association between BMI and lung function seems to be explained by the fact that there is an important overlap between overall obesity and central obesity. There is further a positive association between the level of physical activity and lung function that cannot be explained by general or central obesity.

The finding of lower lung function in obese subjects (by BMI) is in accordance with several previous studies $[4-6,8,27]$. However, in one of the previous studies there was a positive association between BMI and lung function in normal weight subjects [27]. Moreover, in the study by WANG et al. [5], $\mathrm{FEV}_{1}$ and FVC were significantly higher in normal weight subjects than in those that were underweight. When it comes to the impact of WC on lung function, previous results have been even more uniform; moreover, an association between increased WC and reduced lung function has been reported both in children $[4,28]$ and in adults $[8,27,29]$. A systematic review has also concluded that WC tends to be inversely associated with $\mathrm{FEV}_{1}$ and FVC [11]. The study by LEONE et al. [29] focusing on metabolic syndrome found that abdominal obesity was independently associated with a restrictive ventilatory pattern. However, their population was younger (46 years of age versus 60 years of age) and contained four times more current smokers (32\% versus $8 \%)$ than in our study. 

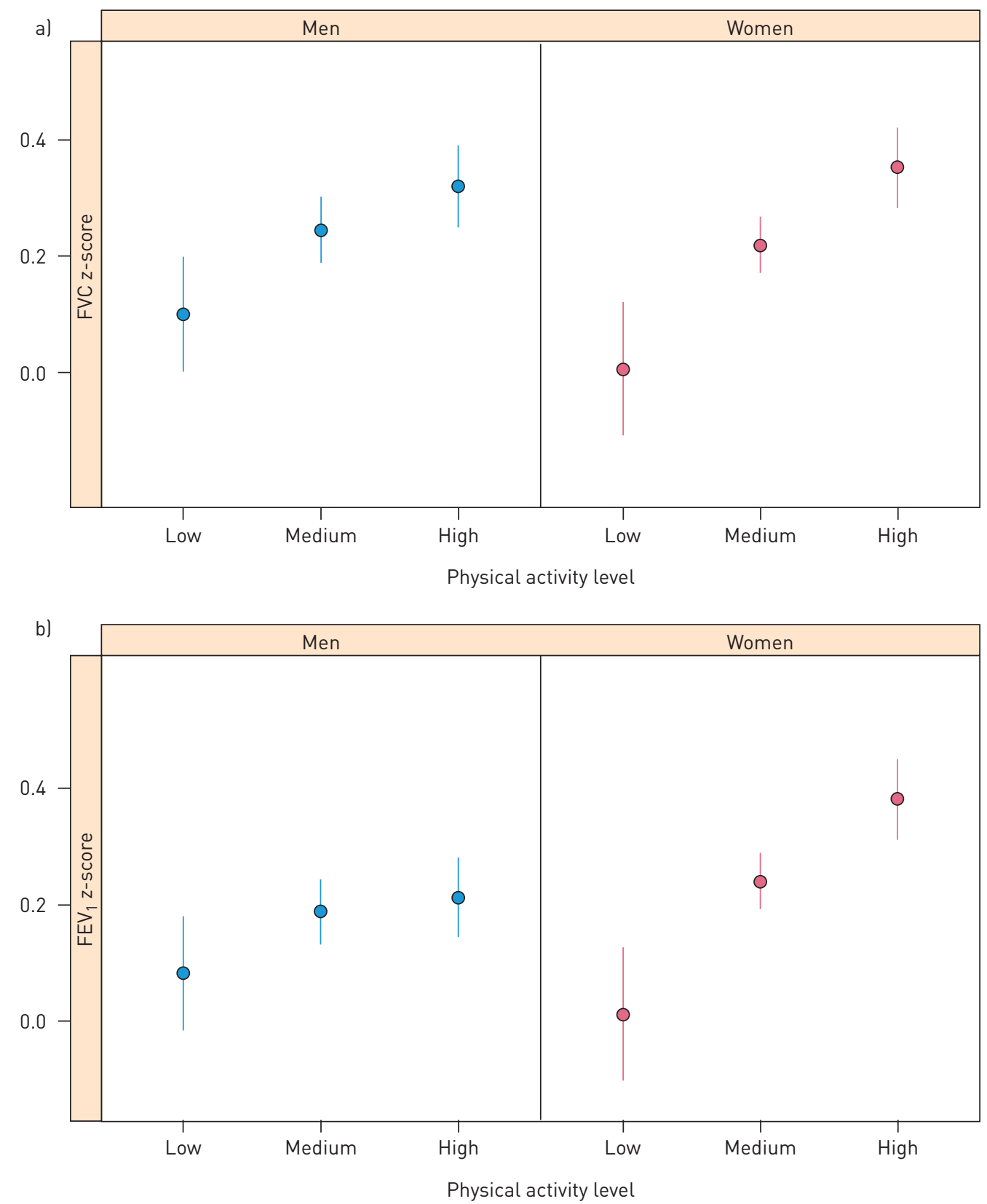

FIGURE 3 a) Mean forced vital capacity (FVC) z-scores and $95 \%$ confidence intervals (Cls) for different categories of physical activity. b) Mean forced expiratory volume in $1 \mathrm{~s}\left(\mathrm{FEV}_{1}\right)$ z-scores and $95 \% \mathrm{Cls}$ for different categories of physical activity. Mean values and $95 \% \mathrm{Cls}$ were adjusted for body mass index (BMI), waist circumference (WC), gender, smoking status and education. Age was not included in the models since it was already adjusted for in the predicted values used as outcome variables.

As far as we know, the interaction between BMI and central obesity with lung function has not previously been analysed in a large population-based sample. Our results indicate that in the absence of central obesity, a high BMI is not related to restrictive lung function impairment but rather a higher lung function. One possible explanation for the positive association between BMI and pulmonary function could be that subjects that are large already during childhood have larger lungs. This theory is supported by the findings of Byberg et al. [4] who found that from birth, weight-related anthropometric measures were positively associated with FVC and $\mathrm{FEV}_{1}$ at 12.8 years of age. Central obesity, on the other hand, is often acquired over time and may primarily decrease lung volume, as it may restrict diaphragm movement and limit lung expansion [30]. A reduction in functional residual capacity (FRC) due to mass load of adipose tissue around the rib cage and abdomen, and in the visceral cavity, might be one of the main mechanisms [31]. 
In this study, we also found an association between low physical activity and low FEV $\mathrm{F}_{1}$ and FVC. This result is in accordance with results from the ECRHS and data from the Copenhagen City Study [13, 14, 32, 33]. Fuertes et al. [13-33] found that vigorous physical activity was associated with better lung function among smokers and LUZAK et al. [34] studied a population of 341 healthy subjects (mean age 57 years) and physical activity was assessed using accelerometers and a weekly diary. They found effects on pulmonary function for the total population and smokers for the highest quartiles but not for non-smokers. In our population, we also found that obese subjects were more likely to be physically inactive. This supports the hypothesis that the association between obesity and impaired lung function may partly be mediated through physical inactivity [12]. Another possibility could be that the association is due to reverse causation: people with chronic lung disease or poor lung function and lack of exercise develop high WC [35]. However, given the overall normal lung function in this population-based sample and that the association between physical activity and lung function was significant also when adjusting for BMI and WC, other mechanisms also seem to be involved.

The strengths of this study include not only the large population but also that we have the measured data of weight, height, WC and lung function, especially considering that $\mathrm{FEV}_{1}$ and $\mathrm{FVC}$ are a function of height. There are studies showing that the difference between actual and self-reported height may be up to $6.9 \mathrm{~cm}$ and are generally largest in elderly subjects [21]. Moreover, the large sample size and detailed assessment of potential confounders, as well as effect modifiers, also facilitate our demonstration of the independent effect of central obesity on pulmonary function. RCS were used to detect the possible nonlinear dependency of the relationship between lung function and BMI level, using three knots at pre-specified locations according to the percentiles of the distribution of BMI (the 10th, 50th and 90th percentiles) [15].

There are, however, some limitations. Lung function tests produce occasion specific results, which not only reflect the presence or absence of respiratory disease but are also influenced by the time of day, daily and seasonal variations [36]. Our findings were obtained mainly in caucasian Swedish men and women. As such, they may be less generalisable to other populations or ethnic groups. Despite adjustments for possible confounders, we could not totally rule out residual confounding. Due to the cross-sectional design of the study, no conclusions on causality can be drawn.

The population with missing data on weight or height was excluded in this study. This could be a potential selection bias. However, when comparing the characteristics of this excluded population and the studied population, there was no significant difference in the associations of lung function between these two groups. Therefore, this selection bias is less likely. Finally, participants with chronic respiratory diseases, in particular asthma and COPD, were included in this study. However, the associations found between lung function, BMI and central obesity did not change when we excluded participants with asthma and COPD (data not shown).

In conclusion, BMI and central obesity are both related to lung function in middle-aged and elderly adults. However, the association of BMI with lung function is dependent on the presence of central obesity. There is a positive association between BMI and lung function as long as there is no central obesity. On the other hand, central obesity is more directly a restrictive factor and is associated with impaired lung function. There is further an association between physical activity and lung function that could not be explained by general obesity or central obesity. We suggest that central obesity should be taken into account when assessing patients using lung function variables.

Conflict of interest: None declared.

Support statement: We thank the Swedish Research Council for supporting the strategic research network Epidemiology for Health (EpiHealth) and thereby the EpiHealth screening cohort. Funding information for this article has been deposited with the Crossref Funder Registry.

\section{References}

1 Ng M, Fleming T, Robinson M, et al. Global, regional, and national prevalence of overweight and obesity in children and adults during 1980-2013: a systematic analysis for the Global Burden of Disease Study 2013. Lancet 2014; 384: 766-781.

2 Corona G, Lee DM, Forti G, et al. Age-related changes in general and sexual health in middle-aged and older men: results from the European Male Ageing Study (EMAS). J Sex Med 2010; 7: 1362-1380.

3 Mafort TT, Rufino R, Costa CH, et al. Obesity: systemic and pulmonary complications, biochemical abnormalities, and impairment of lung function. Multidiscip Respir Med 2016; 11: 28.

4 Byberg KK, Mikalsen IB, Eide GE, et al. The associations between weight-related anthropometrics during childhood and lung function in late childhood: a retrospective cohort study. BMC Pulm Med 2018; 18: 10.

5 Wang S, Sun X, Hsia TC, et al. The effects of body mass index on spirometry tests among adults in Xi'an, China Medicine (Baltimore) 2017; 96: e6596.

6 Melo LC, Silva MA, Calles AC. Obesity and lung function: a systematic review. Einstein (Sao Paulo) 2014; 12 $120-125$. 
7 Hodgson LE, Murphy PB, Hart N. Respiratory management of the obese patient undergoing surgery. J Thorac Dis 2015; 7: 943-952.

8 Ochs-Balcom HM, Grant BJ, Muti P, et al. Pulmonary function and abdominal adiposity in the general population. Chest 2006; 129: 853-862.

9 Klein S, Allison DB, Heymsfield SB, et al. Waist circumference and cardiometabolic risk. Diabetes Care 2007; 30: $1647-1652$.

10 Saxena Y, Sidhwani G, Upmanyu R. Abdominal obesity and pulmonary functions in young Indian adults: a prospective study. Indian J Physiol Pharmacol 2009; 53: 318-326.

11 Wehrmeister FC, Menezes AM, Muniz LC, et al. Waist circumference and pulmonary function: a systematic review and meta-analysis. Syst Rev 2012; 1: 55.

12 Leinaar E, Alamian A, Wang L. A systematic review of the relationship between asthma, overweight, and the effects of physical activity in youth. Ann Epidemiol 2016; 26: 504-510.

13 Fuertes E, Carsin AE, Antó JM, et al. Leisure-time vigorous physical activity is associated with better lung function: the prospective ECRHS study. Thorax 2018; 73: 376-384.

14 Garcia-Aymerich J, Lange P, Benet $\mathrm{M}$, et al. Regular physical activity modifies smoking-related lung function decline and reduces risk of chronic obstructive pulmonary disease: a population-based cohort study. Am J Respir Crit Care Med 2007; 175: 458-463.

15 Desquilbet L, Mariotti F. Dose-response analyses using restricted cubic spline functions in public health research Stat Med 2010; 29: 1037-1057.

16 Lind L, Elmståhl S, Bergman E, et al. EpiHealth: a large population-based cohort study for investigation of gene-lifestyle interactions in the pathogenesis of common diseases. Eur J Epidemiol 2013; 28: 189-197.

17 Cai GH, Janson C, Theorell-Haglow J, et al. Both weight at age 20 and weight gain have an impact on sleep disturbances later in life: results of the EpiHealth study. Sleep 2018; 41: zsx176.

18 Cai GH, Theorell-Haglow J, Janson C, et al. Insomnia symptoms and sleep duration and their combined effects in relation to associations with obesity and central obesity. Sleep Med 2018; 46: 81-87.

19 Expert Panel on Detection, Evaluation, and Treatment of High Blood Cholesterol in Adults. Executive summary of the third report of the National Cholesterol Education Program (NCEP) expert panel on detection, evaluation, and treatment of high blood cholesterol in adults (adult treatment panel III). JAMA 2001; 285: 2486-2497.

20 Almqvist C, Adami HO, Franks PW, et al. LifeGene-a large prospective population-based study of global relevance. Eur J Epidemiol 2011; 26: 67-77.

21 Quanjer PH, Stanojevic S, Cole TJ, et al. Multi-ethnic reference values for spirometry for the 3-95-yr age range: the global lung function 2012 equations. Eur Respir J 2012; 40: 1324-1343.

22 Lytras T. Rspiro: spirometry equations for $\mathrm{R}$ ( $\mathrm{R}$ package version 0.1 ). The Comprehensive R Archive Network, 2017. Date last accessed: November 04, 2019.

23 Byberg L, Melhus H, Gedeborg R, et al. Total mortality after changes in leisure time physical activity in 50 year old men: 35 year follow-up of population based cohort. Br J Sports Med 2009; 43: 482-487.

24 Liu Q, Shepherd BE, Li C, et al. Modeling continuous response variables using ordinal regression. Stat Med 2017; 36: 4316-4335.

25 R: a language and environment for statistical computing. Vienna, The R Foundation, 2019. www.r-project.org Date last accessed: November 04, 2019.

26 Harrell FE Jr. Rms: regression modeling strategies (R package version 5.1-3.1). The Comprehensive R Archive Network, 2019. https://cran.r-project.org/package=rms Date last accessed: November 04, 2019.

27 Chen Y, Rennie D, Cormier YF, et al. Waist circumference is associated with pulmonary function in normal-weight, overweight, and obese subjects. Am J Clin Nutr 2007; 85: 35-39.

28 Bekkers MB, Wijga AH, de Jongste JC, et al. Waist circumference, BMI, and lung function in 8-year-old children: the PIAMA birth cohort study. Pediatr Pulmonol 2013; 48: 674-682.

29 Leone N, Courbon D, Thomas F, et al. Lung function impairment and metabolic syndrome: the critical role of abdominal obesity. Am J Respir Crit Care Med 2009; 179: 509-516.

30 Biring MS, Lewis MI, Liu JT, et al. Pulmonary physiologic changes of morbid obesity. Am J Med Sci 1999; 318 : 293-297.

31 Salome CM, King GG, Berend N. Physiology of obesity and effects on lung function. J Appl Physiol 2010; 108: 206-211.

32 Carsin AE, Fuertes E, Schaffner E, et al. Restrictive spirometry pattern is associated with low physical activity levels. A population based international study. Respir Med 2019; 146: 116-123.

33 Fuertes E, Markevych I, Jarvis D, et al. Residential air pollution does not modify the positive association between physical activity and lung function in current smokers in the ECRHS study. Environ Int 2018; 120: 364-372.

34 Luzak A, Karrasch S, Thorand B, et al. Association of physical activity with lung function in lung-healthy German adults: results from the KORA FF4 study. BMC Pulm Med 2017; 17: 215.

35 Pan J, Xu L, Lam TH, et al. Association of adiposity with pulmonary function in older Chinese: Guangzhou Biobank Cohort Study. Respir Med 2017; 132: 102-108.

36 Borsboom GJ, van Pelt W, van Houwelingen HC, et al. Diurnal variation in lung function in subgroups from two Dutch populations: consequences for longitudinal analysis. Am J Respir Crit Care Med 1999; 159: 1163-1171. 